Published in Eating and Weight Disorders, 2019 which should be cited to refer to this work

DOI : $10.1007 /$ s40519-019-00645-4

Title:

\title{
Factors associated with disordered eating behaviors and attitudes in older women
}

\section{Authors and affiliations:}

Isabelle Carrard - Department of Nutrition and dietetics, School of Health Sciences, University of Applied Sciences and Arts Western Switzerland (HES-SO), Geneva, Switzerland ORCID-profile https://orcid.org/0000-0002-2384-6696

Stéphane Rothen - Geneva University Hospitals, Geneva, Switzerland ORCID-profile https://orcid.org/0000-0003-3891-277X

Corresponding author:

Isabelle Carrard - isabelle.carrard@hesge.ch - +4122.388.34.60

\section{Acknowledgements:}

An internal grant was received from the University of Applied Science and Arts Western Switzerland (HES-SO) scientific committee for research in health. 


\section{ABSTRACT}

\section{Purpose}

The present study explored the potential factors associated with disordered eating behaviors and attitudes in older women.

\section{Methods}

Women aged 60-75 were recruited in the community $(n=203)$ and completed questionnaires. The Eating Disorder Examination-Questionnaire (EDE-Q) was used to evaluate disordered eating behaviors and attitudes. The independent variables were BMI, age, importance of appearance, importance of body competence, cognitive reappraisal, and fear of age-related appearance changes. Spearman correlation analyses and zero-inflated negative binomial regression models were used to analyze the data.

\section{Results}

BMI was positively associated with EDE-Q restraint, EDE-Q eating concern and EDE-Q frequency of objective binge-eating episodes. Importance of appearance was positively related to EDE-Q restraint, and fear of age-related appearance changes to EDE-Q eating concern and objective binge-eating episodes. Cognitive reappraisal was negatively associated with EDE-Q eating concern and excessive exercise in bivariate associations but the relationships disappeared in the multivariate analyses.

\section{Conclusions}

$\mathrm{BMI}$, importance of appearance and fear of age-related appearance changes turned out to be positively associated with eating disordered behaviors and attitudes, similarly to what can be observed in middle-aged samples. However, the role of cognitive reappraisal was unclear and should be investigated further.

\section{Level of evidence:}


level V-cross-sectional descriptive study

\section{Keywords:}

women, aging, risk factors, eating disorders, disordered eating, zero-sensitive 


\section{INTRODUCTION}

Disordered eating in older women has become a topic of attention, with a sufficient number of publications to recently produce two successive literature reviews $[1,2]$. It appears that body image disturbances and eating disorders are not only characteristics observed in young women. The assessment of eating disorders symptoms in community women has suggested that with age (50 and above), binge eating was rather prevalent (3.5\%), while low body mass index (BMI) became rare (0.1\%) [3]. Dietary restraint to avoid weight gain had been reported by $56 \%$ of a sample of women aged 60 to 70 years old [4]. Dieting to lose weight even when not needed (i.e. at a $\mathrm{BMI}<25$ ) was also noticed, reaching $62 \%$ of women older than 65 who wanted to lose weight when $65 \%$ of them were at normal weight [5]. An increase of disordered eating behaviors was observed in two community studies conducted in Australia, and this concerned older (>55 years) participants as well [6]. Moreover, a recent two-stage study showed that point prevalence of eating disorders among women aged above 65 years old $(65-94)$ was $3.25 \%(1.83-5.7,95 \% \mathrm{Cl})$, with bingeeating disorder (BED) being the most prevalent [7]. Whether caused by excessive weight loss or obesity, consequences of eating disorders for health and quality of life should not be ignored in older women [8].

Disordered eating attitudes, that is concerns about weight and shape, have been documented too in aging women. Body dissatisfaction and "feeling fat" were reported by older women even at normal weight [4]. A large community study has shown that body dissatisfaction was rather constant in women across ages, at least up to 75 years old, when BMI was controlled for [9]. A study which included 796 participants aged between 18 and 64 years old showed that $83.2 \%$ of participants wanted to change their appearance, and that it slightly increased with age and BMI [10]. However, even if women aged 66 and older showed 
similar levels of body dissatisfaction as women aged 50 to 65, they were less likely to engage in weight-related behaviors [11]. Consequences of body dissatisfaction seem to change with age because of a decrease of the importance of appearance [12]. As summarized by Tiggemann [13], "with age women's bodies deteriorate, they remain equally dissatisfied, but it matters less to them" (p. 35). In parallel, body appreciation would increase with age, in spite of a constant level of body dissatisfaction [14]. It has also been posited that other factors such as cognitive control (lowered expectations and cognitive reappraisal) would compensate this increase and even alleviate the effect of aging on body dissatisfaction [15]. Webster \& Tiggemann [15] compared young (20-34), middle-aged (35-49) and older (50-65) women and observed that body dissatisfaction and body importance remained constant across age groups, but that cognitive control increased with age and was a protective mechanism of the relationship between body dissatisfaction and self-esteem.

Factors that might be associated with disordered eating behaviors in older women have been explored in few studies. Perfectionism, depression, and sociocultural pressures to be thin were associated with eating pathology in women aged 60 to 90 , similarly as what is observed among their younger counterparts [16]. However, other factors such as body dissatisfaction, life stress, and aging-related concerns about appearance, did not show any statistical association with disordered eating in this population [16]. In a sample of postmenopausal women aged 44 to 85, BMI, a lower ideal weight than one's current weight, body dissatisfaction and physical quality of life were associated with a higher risk of disordered eating, whereas an older age was associated with a lower risk [17].

Besides, a growing body of research has examined this issue but in middle-aged women. Even if, in a sample of women aged 17-64, an older age was found to be associated with lower reported dieting and better psychological functioning [18], a review on the 
predictors associated with body dissatisfaction and disordered eating concluded that most factors identified for young women, such as BMI or importance of appearance, could also apply for middle-aged women [19]. Specific factors, such as menopausal status and aging anxiety also seemed to play a role in middle-aged women [19]. Besides that, higher levels of weight suppression (highest past adult weight - current weight) and of weight elevation (current weight - lowest past adult weight) were found to be associated with disordered eating behaviors [20]. McLean, Paxton and Wertheimer also showed that importance of appearance, $\mathrm{BMI}$ and self-care were predictors of eating disorders behaviors and attitudes assessed with the EDE-Q in sample of 200 women aged 35 to 65 years old [21]. They also found relationships between cognitive reappraisal, EDE-Q restraint, and shape concern, and between importance of body function and EDE-Q restraint. The importance of body function, also called body competence, is another factor that could gain in importance over body appearance when getting older [22].

In the present cross-sectional study, called the "TWIGGY project", we were interested in factors associated with disordered eating behaviors and attitudes in women aged 60 to 75 years old. These women belong to an age group which has lived with societal pressure for thinness during their whole life, since the "TWIGGY culture" (named this way after the name of the fashion model iconic of the '60s) started when they were adolescents or young women. Moreover, they have experienced many societal changes during their life, such as the right to vote (in Switzerland women obtained the right to vote at federal level in 1971), or birth control, whose effects on aging are not known [23]. In accordance with the aforementioned studies, we posited that BMI, which has been associated with higher risk of disordered eating in post-menopausal women [17], importance of appearance, and aging anxiety would be positively associated - and importance of body competence (over body 
appearance), and cognitive reappraisal would be negatively associated - with disordered eating and attitudes in older women. We decided to focus more specifically on the two EDE$Q$ subscales assessing restraint and eating concern for the regression analyses, because of we posited that the constructs of EDE-Q weight concern and shape concern may overlap with the independent variables assessing appearance concerns. Then, because binge-eating was noticed as prevailing over low BMI in older women [3], we also included binge eating episodes, vomiting, laxatives use and excessive exercises as dependent variables.

\section{METHODS}

\section{Participants}

Recruitment started in August 2017 and closed in March 2018. It took place in the French-speaking part of Switzerland and the surrounding region of France. Participants were recruited through advertisements published in magazines targeting seniors or women of any age (excluding fashion or beauty magazines), and in associations or social activity clubs for seniors. The advertisement called for volunteers to fill in questionnaires exploring body image, eating behavior, and psychological health in older women. Inclusion criteria were to be a French-speaking woman aged between 60 and 75 years old, who had spent most of one's life in a Western country. The regular consumption of medication interfering with appetite was an exclusion criterion. Out of a total of 245 women who made contact to participate in the study, 221 completed the questionnaires. We retained 203 participants with complete data on the variables of interest. Participants' mean age was 67 and mean BMI was 23.7, which is lower than the mean BMI of 25.2 reported in Switzerland by women aged 65-75 [24], but close to the BMI of 23.2 reported by women with a tertiary level of education. Of note, 95 (47.3\%. 2 missing values) participants reported a tertiary (training after high school) level of education in this sample, 92 (45.8\%) a secondary level and 14 
(7.0\%) a primary level of education. Current somatic illnesses were reported by 67 (33\%) participants and current psychiatric disorders by 14 (7\%) participants, mainly depression and anxiety, but no active eating disorder was reported. Eighty-seven percent $(n=177)$ of participants reported that they exercised regularly, at least once a week, and $16 \%(n=32)$ reported that they were on a diet, of whom 21 had a normal BMI (16\% of the normal BMI category).

\section{Procedure}

Participants interested in taking part in the study had to phone a research assistant who explained the research and checked the inclusion/exclusion criteria. The questionnaires could be completed online with LimeSurvey ${ }^{\circledast}$ or sent on paper with a return stamped envelope. Each participant received a code to anonymize the data. They all received an information sheet and had to sign and return a written informed consent. Participants were contacted twice if no answer had been received before being considered as drop outs. After questionnaire completion and informed consent reception, the participant was sent a voucher of CHF 20.-(EUR 18.-, USD 20.-, financed by the internal grant which funded this study) for a department store as compensation. The protocol had been approved by the Geneva research ethical committee.

\section{$\underline{\text { Measures }}$}

Disordered eating behaviors and attitudes were assessed with the Eating Disorder Examination Questionnaire v6.0 (EDE-Q) $[25,26]$ : this 28 -item scale assesses four subscales that are considered to be core dimensions of the psychopathology of eating disorders: restraint (e.g. Have you been deliberately trying to limit the amount of food you eat to influence your shape or weight (whether or not you have succeeded)?), eating concern (e.g. Have you had a definite fear of losing control over eating?) , shape concern (e.g. Have you 
had a definite fear that you might gain weight?) and weight concern (e.g. Has your weight influenced how you think about (judge) yourself as a person?). Each subscale is composed of Likert-scale items scoring from 0 (no days/not at all) to 6 (everyday/markedly). A total score can be computed with the four subscales. Six items also evaluate the frequency of binging and compensatory behaviors. We used four of them as dependent variables: frequencies of objective binge-eating episodes, vomiting, laxatives and excessive exercise. Two questions that ask for the participant's weight and height were used to calculate the BMI $\left(\mathrm{kg} / \mathrm{m}^{2}\right)$. Cronbach's alphas in the present study were acceptable, with 0.82 (restraint), 0.78 (eating concern), 0.88 (shape concern) and 0.76 (weight concern).

Importance of appearance was assessed with the Multidimensional Body SelfRelations Questionnaire - Appearance Scales (MBSRQ-AS) [27,28]: this 34-item scale assesses attitudes towards different aspects of the construct of body image. This short version of the original 69 -item MBSRQ contains five subscales. In this study we only used the appearance orientation subscale to assess importance of appearance. The score is the result from a mean calculation on 12 items (e.g. Before going out in public, I always notice how I look) ranging from 1 (definitely disagree) to 5 (definitely agree). Cronbach's alpha was 0.86 .

Importance of body competence over appearance was assessed with the SelfObjectification Questionnaire (SOQ) [29]: This 10-item scale contains appearance-based (e.g. When considering your physical self-concept... What rank do you assign to sex appeal?) and competence-based items (e.g. ...What rank do you assign to health?) that have to be ranked in order of importance, from 9 (greatest impact) to 0 (least impact). Two sub-scores importance of appearance and importance of competence - are calculated and then subtracted. In the present study, we subtracted the score of body appearance from that of 
body competence and added 25 to always obtain a positive score (ranging from 0 to 50 ). The higher was the score, the greater was the importance of body competence over body appearance for one's physical self-concept.

Cognitive reappraisal was assessed with the Cognitive Reappraisal scale [21]: This 11item scale was developed by McLean et al. to assess acceptance of age-related appearance changes in their study. The respondents had to express their agreement with each item (e.g. It is realistic to accept changes in my body due to age) using a Likert-scale ranging from 1 (strongly disagree) to 5 (strongly agree). A higher score indicates higher cognitive reappraisal. In the present study Cronbach's alpha was 0.91 .

Fear of age-related appearance changes (aging anxiety) was assessed with the Anxiety about aging scale (AAS) [30]: This 20-item scale includes four subscales assessing various dimensions of anxiety about aging: fear of old people, psychological concerns, physical appearance concerns, fear of loss. For the present study we used the subscale physical appearance concerns which represent the fear of seeing changes in one's looks with aging. It contains five items (e.g. I have never dreaded looking old) that the respondent had to assess on a Likert-scale from 1 (strongly agree) to 5 (strongly disagree). The score corresponds to the sum of these items and the higher the score, the higher the aging anxiety. In the present study, Cronbach's alpha was 0.74 .

Demographics: Data were collected on age, life context, health, current dieting and practice of physical activity.

French versions of these questionnaires were used. Translated versions of the EDE-Q and MBSRQ-AS were available and had been the subject of psychometric assessment $[26,28]$. A procedure of translation and back-translation with a professional translator was carried out to obtain French versions of the SOQ, AAS and Cognitive reappraisal scale. The 
psychometric properties of the French versions of these three questionnaires have not been evaluated, except for the aforementioned internal reliability coefficients (Cronbach's alpha).

\section{Data Analysis}

Missing values were imputed with the subscales means when their number did not exceed $10 \%$ of the items of the questionnaire. Data were checked for normality prior to analysis. EDE-Q variables appeared to be positively skewed with an excess number of zeros. Deviation from normality was too marked to transform the variables. For this reason, we used median in addition to the mean in the descriptive statistics, and Spearman's correlations to analyze the bivariate relationships between variables. We used count procedures (Poisson or negative binomial distributions) which represent a valuable option to deal with positively skewed data and assume that the dependent variable is distributed according to discrete count. We have based our procedure according to the recommendations from Schaumberg et al. [31], who described the risks of validity and reliability of outcomes obtained with OLS regression analyses on positively skewed data with an excess number of zeros. To this end, we computed EDE-Q subscales scores using the sum of each item composing it. Zero-inflated models are used when the dependent variable show a number of zeros higher than expected in a Poisson or negative binomial model. In order to choose the best model to fit our data, we compared with a likelihood-ratio test the fit of a Poisson, Quasi-Poisson, Negative binomial, Hurdle-Poisson, Hurdle-negative binomial, zeroinflated Poisson and Zero-inflated negative binomial model. The best fit was found for the zero-inflated negative binomial regression model. The output of zero-inflated negative binomial models comprises two components: the first one is a negative binomial count model whose estimates can be interpreted as the strength of the relationship between the predictor and the dependent variable. The second component is a binary model (i.e. a 
logistic regression) which indicates the probability of answering 0 to the dependent variable.

R version 3.5.1. software program was used to conduct regression models (packages pscl [32]: https://cran.r-project.org/web/packages/pscl/vignettes/countreg.pdf).

\section{RESULTS}

Descriptive statistics are displayed in Table 1. The EDE-Q subscales deviations between means and medians illustrate the floor effect observed for the dependent variables. The independent variables were normally distributed. The means and standard deviations indicated that importance of appearance was present with the majority of participants answered between 'neither agree nor disagree' and 'mostly agree', importance of body competence was higher than importance of body appearance but with a great variation between participants, cognitive reappraisal was rather predominant among participants who answered on the side of 'agree' on the cognitive reappraisal scale, and fear of age-related appearance changes was low ('disagree') to medium ('neither agree nor disagree') among participants. 
Table 1. Summary statistics for the whole sample $(n=203)$

\begin{tabular}{|c|c|c|c|c|c|c|}
\hline & Mean & SD & Median & Minimum & $\mathbf{N}$ with 0 & Maximum \\
\hline EDE-Q restraint & 1.08 & 1.39 & 0.40 & 0.0 & 77 & 6.00 \\
\hline EDE-Q eating concern & 0.33 & 0.78 & 0.00 & 0.0 & 133 & 5.00 \\
\hline EDE-Q shape concern & 1.63 & 1.49 & 1.25 & 0.0 & 26 & 5.88 \\
\hline EDE-Q weight concern & 1.20 & 1.33 & 0.60 & 0.0 & 54 & 5.40 \\
\hline EDE-Q total score & 1.06 & 1.04 & 0.66 & 0.0 & 17 & 4.64 \\
\hline EDE-Q objective binge-eating episodes & 1.19 & 3.74 & 0.00 & 0.0 & 162 & 28 \\
\hline EDE-Q vomiting & 0.03 & 0.321 & 0.00 & 0.0 & 200 & 4 \\
\hline EDE-Q laxatives & 0.09 & 0.822 & 0.00 & 0.0 & 199 & 10 \\
\hline EDE-Q excessive exercise & 1.38 & 4.74 & 0.00 & 0.0 & 173 & 28 \\
\hline Age & 67.31 & 4.43 & 67.00 & 59.00 & & 76.00 \\
\hline $\mathrm{BMI}$ & 23.74 & 4.26 & 22.99 & 14.20 & & 38.39 \\
\hline MBRSQ-AS importance of appearance & 3.66 & 0.61 & 3.66 & 1.67 & & 5.00 \\
\hline SOQ importance of body competence & 33.71 & 11.37 & 34.00 & 0.00 & & 50.00 \\
\hline Cognitive reappraisal & 4.02 & 0.65 & 4.09 & 1.73 & & 5.00 \\
\hline AAS Fear of age-related appearance changes & 2.47 & 0.80 & 2.40 & 1.00 & & 4.80 \\
\hline
\end{tabular}

Note. Note. AAS Anxiety about Aging Scale; BMI Body mass index; EDE-Q Eating Disorder Examination-Questionnaire;

MBSRQ-AS Multidimensional Body Self-Relations Questionnaire - Appearance Scales; SOQ Self-Objectification Questionnaire. 
EDE-Q objective binge eating episodes were mentioned by 41 (20.2\%) participants. The frequency was occasional (less than once a week) for 23 (11.3\%) participants. Eighteen (8.9\%) reported at least one objective binge eating episode per week, up to everyday (one participant). Purging behaviors were very rarely used: three (1.5\%) participants mentioned vomiting and four (2\%) taking laxatives. Excessive exercise on the contrary was reported by a higher frequency of participants ( $n=30,14.8 \%)$, from once a month to every day.

Similarly to what McLean et al. [21] examined in their sample of middle-aged women, we investigated the probable case of eating disorders in using the criteria proposed by Mond, Hay, Rodgers, Owen, and Beumont (objective binge eating episode and/or exercising for weight or shape reasons at least once per week in addition to a score of $\geq 2.3$ on the global scale of the EDE-Q; ) [33]. Nine (4.4\%) participants fit these criteria considered together.

Spearman's correlations are displayed in Table 2. EDE-Q frequency of vomiting and laxatives were not included because only three and four participants answered positively. Regarding significant correlations with the EDE-Q dependent variables, BMI and AAS fear of age-related appearance changes were positively correlated with EDE-Q restraint, eating concern, and objective binge-eating episodes. AAS fear of age-related appearance changes was moreover positively correlated with excessive exercise. MBRSQ-AS importance of appearance was positively correlated with EDE-Q restraint and excessive exercise. Cognitive reappraisal was negatively correlated with EDE-Q eating concern and excessive exercise. Note that age and SOQ importance of body competence over appearance were not significantly correlated with any of the EDE-Q variables.

Regarding other interesting significant correlations, as posited EDE-Q shape concern, EDE-Q weight concern and EDE-Q total score were positively correlated with BMI, MBRSQ-AS 
importance of appearance (except for EDE-Q weight concern), and AAS fear of age-related appearance changes; and they were negatively correlated with cognitive reappraisal, showing an overlap of the constructs. Besides that, an older age was positively correlated with a higher importance of body competence over appearance and higher cognitive reappraisal. 
Table 2. Spearman's correlations between EDE-Q subscales and behaviours and independent variables $(n=203)$

\begin{tabular}{|c|c|c|c|c|c|c|c|c|c|c|c|c|}
\hline & 1. & 2. & 3. & 4. & 5. & 6. & 7. & 8. & 9. & 10. & 11. & 12. \\
\hline 1. EDE-Q restraint & - & & & & & & & & & & & \\
\hline 2. EDE-Q eating concern & $.37 * *$ & - & & & & & & & & & & \\
\hline 3. EDE-Q shape concern & $.61^{* *}$ & $.58^{* *}$ & - & & & & & & & & & \\
\hline 4. EDE-Q weight concern & $.58 * *$ & $.56^{* *}$ & $.83^{* *}$ & - & & & & & & & & \\
\hline 5. EDE-Q total score & $.78^{* *}$ & $.62 * *$ & $.93^{* *}$ & $.89 * *$ & - & & & & & & & \\
\hline $\begin{array}{l}\text { 6. EDE-Q objective binge-eating } \\
\text { episodes }\end{array}$ & $.24 * *$ & $.58^{* *}$ & $.46^{* *}$ & $.40 * *$ & $.44^{* *}$ & - & & & & & & \\
\hline 7. EDE-Q excessive exercise & $.21 * *$ & $.26 * *$ & $.20 * *$ & .14 & $.21 * *$ & $.25 * *$ & - & & & & & \\
\hline 8. Age & -.08 & -.13 & -.13 & -.13 & -.14 & .02 & -.09 & - & & & & \\
\hline 9. BMI & $.38 * *$ & $.31 * *$ & $.49 * *$ & $.53^{* *}$ & $.53^{* *}$ & $.20 * *$ & -.10 & -.08 & - & & & \\
\hline $\begin{array}{l}\text { 10. MBRSQ-AS importance of } \\
\text { appearance }\end{array}$ & $.24 * *$ & .11 & $.23 * *$ & .14 & $.20 * *$ & .02 & $.17^{*}$ & .02 & -.03 & - & & \\
\hline $\begin{array}{l}\text { 11. SOQ importance of body } \\
\text { competence }\end{array}$ & -.05 & -.02 & -.08 & -.06 & -.06 & -.03 & -.02 & $.17^{*}$ & .11 & $-.30 * *$ & - & \\
\hline 12. Cognitive reappraisal & -.09 & $-.23 * *$ & $-.22 * *$ & $-.19 * *$ & $-.20 * *$ & -.06 & $-.15^{*}$ & $.16^{*}$ & .03 & -.06 & $.18^{* *}$ & - \\
\hline $\begin{array}{l}\text { 13. AAS Fear of age-related } \\
\text { appearance changes }\end{array}$ & $.18^{*}$ & $.28 * *$ & $.39 * *$ & $.31^{* *}$ & $.35^{* *}$ & $.19 * *$ & $.17^{*}$ & -.10 & -.00 & $-.20 * *$ & $-.21 * *$ & $-.47^{* *}$ \\
\hline
\end{tabular}
$* p<.05, * * p<.01$, bilateral test

Note. AAS Anxiety about aging scale; BMI Body mass index; EDE-Q Eating Disorder Examination-Questionnaire; MBSRQ-AS Multidimensional Body Self-Relations Questionnaire - Appearance Scales; SOQ Self-Objectification Questionnaire. 
Regression analyses were conducted with independent variables that had shown bivariate correlations with dependent variables. Age and SOQ importance of body competence over appearance were not introduced in the analyses. Odd ratios and relative risks of the zero-inflated negative binomial regression analyses conducted for each of the selected dependent variables EDE-Q restraint, EDE-Q eating concern, EDE-Q objective binge eating episodes and EDE-Q excessive exercise are shown in Table 3. A higher BMI and a higher MBSRQ importance of appearance were significantly associated with a lower probability of obtaining a null score on the EDE-Q restraint subscale. Higher scores of MBSRQ-AS importance of appearance were associated with higher scores of EDE-Q restraint. A higher BMI was associated with a lower probability of obtaining a null score on the EDE-Q eating concern subscale, and the higher were the scores of AAS fear of age-related appearance changes, the higher were those of EDE-Q eating concern. A lower probability of obtaining a null score on the EDE-Q objective binge eating episodes scale was associated with a higher AAS fear of age-related appearance changes. Higher scores of EDE-Q objective binge-eating episodes were associated with a higher BMI. EDE-Q excessive exercise was not associated with any of the independent variables. 
Table 3. Odd ratios (OR)/Relative risks $(\mathrm{RR})$ and confidence intervals $(\mathrm{Cl})$ of the zero-inflated negative binomial regressions

\begin{tabular}{|c|c|c|c|c|c|c|c|c|}
\hline & \multicolumn{2}{|c|}{ EDE-Q restraint } & \multicolumn{2}{|c|}{ EDE-Q eating concern } & \multicolumn{2}{|c|}{$\begin{array}{l}\text { EDE-Q objective binge } \\
\text { eating episodes }\end{array}$} & \multicolumn{2}{|c|}{ EDE-Q excessive exercise } \\
\hline & Binomial & Count & Binomial & Count & Binomial & Count & Binomial & Count \\
\hline & $\mathrm{OR}(\mathrm{Cl})$ & $\mathrm{RR}(\mathrm{Cl})$ & $\mathrm{OR}(\mathrm{Cl})$ & $\mathrm{RR}(\mathrm{Cl})$ & $\mathrm{OR}(\mathrm{Cl})$ & $\mathrm{RR}(\mathrm{Cl})$ & $\mathrm{OR}(\mathrm{Cl})$ & $\mathrm{RR}(\mathrm{Cl})$ \\
\hline BMI & $\begin{array}{l}0.71 * * \\
(0.58-0.88)\end{array}$ & $\begin{array}{l}1.03(0.99- \\
1.08)\end{array}$ & $\begin{array}{l}0.73 * *(0.61- \\
0.89)\end{array}$ & $\begin{array}{l}1.01(0.94- \\
1.08)\end{array}$ & $\begin{array}{l}0.94(0.84- \\
1.06)\end{array}$ & $\begin{array}{l}1.15^{*}(1.01- \\
1.30)\end{array}$ & $\begin{array}{l}1.04(0.93- \\
1.16)\end{array}$ & $\begin{array}{l}0.91(0.83- \\
1.00)\end{array}$ \\
\hline $\begin{array}{l}\text { MBSRQ-AS importance of } \\
\text { appearance }\end{array}$ & $\begin{array}{l}0.43^{*}(0.20- \\
0.89)\end{array}$ & $\begin{array}{l}1.39 *(1.00- \\
1.92)\end{array}$ & $\begin{array}{l}0.58(0.20- \\
1.69)\end{array}$ & $\begin{array}{l}0.88(0.50- \\
1.55)\end{array}$ & $\begin{array}{l}1.16(0.52- \\
2.63)\end{array}$ & $\begin{array}{l}1.50(0.71- \\
3.16)\end{array}$ & $\begin{array}{l}0.51(0.24- \\
1.09)\end{array}$ & $\begin{array}{l}0.67(0.32- \\
1.40)\end{array}$ \\
\hline Cognitive reappraisal & $\begin{array}{l}0.67(0.30- \\
1.49)\end{array}$ & $\begin{array}{l}0.87(0.66- \\
1.16)\end{array}$ & $\begin{array}{l}1.67(0.50- \\
5.52)\end{array}$ & $\begin{array}{l}0.82(0.47- \\
1.40)\end{array}$ & $\begin{array}{l}0.78(0.34- \\
1.83)\end{array}$ & $\begin{array}{l}0.90(0.43- \\
1.88)\end{array}$ & $\begin{array}{l}1.60(0.75- \\
3.40)\end{array}$ & $\begin{array}{l}1.47(0.82- \\
2.63)\end{array}$ \\
\hline $\begin{array}{l}\text { AAS fear of age-related } \\
\text { appearance changes }\end{array}$ & $\begin{array}{l}0.60(0.29- \\
1.23)\end{array}$ & $\begin{array}{l}1.10(0.85- \\
1.44)\end{array}$ & $\begin{array}{l}0.63(0.24- \\
1.65)\end{array}$ & $\begin{array}{l}1.85^{* *}(1.17- \\
2.91)\end{array}$ & $\begin{array}{l}0.38 *(0.17- \\
0.85)\end{array}$ & $\begin{array}{l}0.79(0.40- \\
1.56)\end{array}$ & $\begin{array}{l}0.65(0.34- \\
1.26)\end{array}$ & $\begin{array}{l}0.86(0.48- \\
1.55)\end{array}$ \\
\hline
\end{tabular}

$* p<.05, * * p<.01$

Note. AAS Anxiety about aging scale; BMI Body mass index; EDE-Q Eating Disorder Examination-Questionnaire; MBSRQ-AS

Multidimensional Body Self-Relations Questionnaire - Appearance Scales; SOQ Self-Objectification 


\section{DISCUSSION}

The objective of this study was to explore the factors associated with eating disordered behaviors and attitudes in older women. The EDE-Q criteria proposed by Mond et al. [33] to screen for probable eating disorders in the community selected $4.4 \%$ of the sample. This percentage may seem to appear as considerably lower than that of $17 \%$ found by McLean et al. [21] in their sample aged 35-65. However, McLean et al. [21] underlined that $17 \%$ was higher than percentages usually reported (e.g. $6.3 \%$ in a community sample of women aged 18-45) [33]. Besides, the percentage of $4.4 \%$ was close to the prevalence rate of 3.5\% found in Portuguese women aged 65-94 [7]. Despite this percentage, and in spite of the presence of at least weekly binge eating episodes without the presence of frequent purging behaviors reported by $8.9 \%$ of the participants, none of them mentioned an active eating disorder. It may be that these episodes were not accompanied by the criteria necessary to meet BED diagnosis, but it may also be due to the fact that BED has only recently been introduced in the DSM-5 [34] and is still not systematically screened for or recognized by health care professionals [35]. Women of this age might have suffered from such a disorder without ever being diagnosed at all during their life and would never know that they can ask for a treatment.

Importance of appearance was present in this sample and the high frequency of participants who mentioned being physically active reveals that they took care of their health and fitness. However, a small percentage (16\%) also reported following a diet, whereas they were at a normal BMI. The type of diet (balanced or not) followed was not asked for, and these positive answers may simply reflect that these women were paying attention to what they ate for their health. To restrict excessively one's dietary intake when 
at a normal weight should not be recommended [36], because it can cause somatic and/or psychological negative consequences, particularly as age increases [37].

Regression analyses suggested that, as we hypothesized, BMI was a general predictor of EDE-Q restraint, eating concern and objective binge-eating episodes. A higher BMI was associated with the odd of obtaining a non-null score of restraint and eating concern, and with a higher frequency of objective binge-eating episodes. Then, a higher importance of appearance was associated with the probability of obtaining a non-null score of restraint. As hypothesized, participants for whom the appearance was more important also exhibited more restraint. These results were in line with those obtained in middle-aged and older populations $[17,19,21]$.

Fear of age-related appearance changes was also a significant predictor of disordered eating behaviors and attitudes. A high fear of age-related appearance changes increased the chance of obtaining a frequency other than zero on objective binge-eating episodes. Second, higher fear of age-related appearance changes was associated with higher eating concerns. These results were congruent with those obtained among middle-aged and older samples [19]. Aging anxiety has been associated with drive for thinness, body dissatisfaction, and disordered eating in samples of middle-aged (50-65) and older (>65) women [11]. Moving away from the beauty standards of youth and thinness promoted by the Western society might be associated with body dissatisfaction and eating preoccupation for some of these older women, who belong to a generation exposed to these standards since their adolescence or young adulthood. However, conversely, no influence of aging-related concerns about appearance on eating pathology was found in the study by Midlarsky et al. [16] in which predictors of eating pathology were explored also in older women. Yet, the authors proposed that concerns about aging in their population, which included women 
aged 60 to 90, might have been more focused on overall health and hence decrease the relationship between anxiety of physical changes with age and drive for thinness. Despite the presence of some health issues in our "younger" sample, the focus on the implications of aging for health might become more important after 75 years old.

Age was not correlated with disordered eating behaviors and attitudes in the present sample, but bivariate correlations showed that a higher age was slightly associated with a higher importance of body competence over appearance and to higher cognitive reappraisal. Even if importance of appearance is still prevalent among participants, and even if the body deteriorates with age, it is suggested that consequences on disordered eating behaviors and attitudes might decrease $[13,11]$.

Cognitive reappraisal, which had been proposed as protective factor that appeared with age [15] did not show any effect on the dependent variables when introduced in the multivariate regressions, in spite of significant bivariate correlations with eating concern and excessive exercise. A similar pattern had occurred in McLean et al.'s study [21]. The scale had besides been criticized by its authors who proposed to quantify a frequency of cognitive reappraisal strategies rather than asking for participants' agreement with sentences. This could strengthen and potentially clarify these relationships [21]. However, it may also have been totally mediated by fear of age-related appearance changes.

The protective effect of the importance of body competence did not emerge in the present study, contrary to our hypothesis. In a literature review on body image among Western seniors, Roy and Payette [38] pointed out that several quantitative and qualitative research had highlighted that body competence was more valued that the physical aspects of body image. The authors however wisely warned that this could have positive as well as negative consequences on body dissatisfaction, since body competences also decreased with 
age. This could explain the lack of relationship found between body competence and disordered eating behaviors or attitudes.

Some limitations have to be taken into consideration. The cross-sectional design prevents from determining causal relationships. This study's results are representative of a rather well-educated sample. Moreover, the fact that $87 \%$ of the participants mentioned exercising regularly and the low rate of $33 \%$ of current somatic illness underscore that the study population represents a selected sample of very healthy women. Then, the frequencies of objective binge-eating episodes and excessive exercise were assessed with the EDE-Q, which is a self-report questionnaire. This implies possible misunderstandings of the questions and inflated rates of disordered eating behaviors. The high frequency of 'excessive physical exercise to control one's weight' reported by participants seemed disproportionate in this healthy sample of women. Inflated rates may also be related to the absence of medically diagnosed BED cases in this sample. Finally, only older women were assessed in the present study and no comparison can be drawn with younger women; moreover, the restricted age range of the sample may partly explain the absence of correlations with the EDE-Q variables. One strength of the study was the use of statistical methods that considered the skewness of the dependent variables and the excess number of zeros. Finally, studies conducted in samples of older women are still not common in the literature, but results add on to point out that disordered eating behaviors and attitudes can still be present at an older age, with predictors rather similar to those found among middleaged women.

To summarize and conclude, this study's results suggest that eating disorders behaviors and attitudes can still be encountered among women aged 60 to 75 years old. When problematic, disordered eating seemed to be related to binge eating rather than to 
excessive restraint, as measured by the EDE-Q. A higher BMI was associated with the presence of disordered eating behaviors and attitudes. Higher importance of appearance and fear of age-related appearance changes contributed to the severity of disordered eating. An important implication of these results is that health care professionals should keep in mind the possibility of problematic eating behaviors and attitudes even in older women and screen for them in order to suggest an appropriate treatment if needed, that could focus on fear of age-related appearance changes and importance of appearance.

\section{Compliance with Ethical Standards:}

Funding: I. Carrard received an internal grant to conduct this research from the University of Applied Science and Arts Western Switzerland (HES-SO) scientific committee for research in health (grant number 65900/S-RAD16-47).

Conflict of interest: Isabelle Carrard declares that she has no conflict of interest. Stéphane Rothen declares that he has no conflict of interest.

Ethical approval: All procedures performed in the present study involving human participants were in accordance with the ethical standards of the institutional and/or national research committee and with the 1964 Helsinki declaration and its later amendments or comparable ethical standards.

Informed consent: Written informed consent was obtained from all individual participants included in the study. 


\section{REFERENCES}

1. Mangweth-Matzek B, Hoek HW (2017) Epidemiology and treatment of eating disorders in men and women of middle and older age. Curr Opin Psychiatry 30 (6):446-451.

doi:10.1097/YCO.0000000000000356

2. Mangweth-Matzek B, Hoek HW, Pope HG, Jr. (2014) Pathological eating and body dissatisfaction in middle-aged and older women. Curr Opin Psychiatry 27 (6):431-435. doi:10.1097/YCO.0000000000000102

3. Gagne DA, Von Holle A, Brownley KA, Runfola CD, Hofmeier S, Branch KE, Bulik CM (2012) Eating disorder symptoms and weight and shape concerns in a large web-based convenience sample of women ages 50 and above: results of the Gender and Body Image (GABI) study. Int J Eat Disord 45 (7):832-844. doi:10.1002/eat.22030

4. Mangweth-Matzek B, Rupp Cl, Hausmann A, Assmayr K, Mariacher E, Kemmler G, Whitworth AB, Biebl W (2006) Never too old for eating disorders or body dissatisfaction: a community study of elderly women. Int J Eat Disord 39 (7):583-586

5. Allaz AF, Bernstein M, Rouget P, Archinard M, Morabia A (1998) Body weight preoccupation in middle-age and ageing women: a general population survey. Int J Eat Disord 23 (3):287-294

6. Hay PJ, Mond J, Buttner P, Darby A (2008) Eating disorder behaviors are increasing: findings from two sequential community surveys in South Australia. PloS one 3 (2):e1541. doi:10.1371/journal.pone.0001541

7. Conceicao EM, Gomes FVS, Vaz AR, Pinto-Bastos A, Machado PPP (2017) Prevalence of eating disorders and picking/nibbling in elderly women. Int J Eat Disord5 0 (7):793-800. doi:10.1002/eat.22700 
8. Podfigurna-Stopa A, Czyzyk A, Katulski K, Smolarczyk R, Grymowicz M, Maciejewska-Jeske M, Meczekalski B (2015) Eating disorders in older women. Maturitas 82 (2):146-152. doi:10.1016/j.maturitas.2015.06.036

9. Runfola CD, Von Holle A, Trace SE, Brownley KA, Hofmeier SM, Gagne DA, Bulik CM (2013) Body dissatisfaction in women across the lifespan: results of the UNC-SELF and Gender and Body Image (GABI) studies. Eur Eat Disord Rev 21 (1):52-59. doi:10.1002/erv.2201 10. Vandervoort J, Aime A, Green-Demers I (2015) The monster in the mirror: reasons for wanting to change appearance. Eat Weight Disord 20 (1):99-107. doi:10.1007/s40519-0140160-1

11. Lewis DM, Cachelin FM (2001) Body image, body dissatisfaction, and eating attitudes in midlife and elderly women. Eating disorders 9 (1):29-39. doi:10.1080/106402601300187713 12. Tiggemann M, Lynch JE (2001) Body image across the life span in adult women: the role of self-objectification. Dev Psychol 37 (2):243-253

13. Tiggemann M (2004) Body image across the adult life span: stability and change. Body image 1 (1):29-41. doi:10.1016/S1740-1445(03)00002-0

14. Tiggemann M, McCourt A (2013) Body appreciation in adult women: relationships with age and body satisfaction. Body image 10 (4):624-627. doi:10.1016/j.bodyim.2013.07.003 15. Webster J, Tiggemann M (2003) The relationship between women's body satisfaction and self-image across the life span: the role of cognitive control. J Genet Psychol 164 (2):241252. doi:10.1080/00221320309597980

16. Midlarsky E, Marotta AK, Pirutinsky S, Morin RT, McGowan JC (2018) Psychological predictors of eating pathology in older adult women. J Women Aging 30 (2):145-157. doi:10.1080/08952841.2017.1295665 
17. Goncalves SF, Silva E, Gomes AR (2015) The influence of BMI and predictors of disordered eating and life satisfaction on postmenopausal women. J Women Aging 27 (2):140-156. doi:10.1080/08952841.2014.928496

18. Rohde P, Stice E, Shaw H, Gau JM, Ohls OC (2017) Age effects in eating disorder baseline risk factors and prevention intervention effects. Int J Eat Disord 50 (11):1273-1280. doi:10.1002/eat.22775

19. Slevec JH, Tiggemann M (2011) Predictors of body dissatisfaction and disordered eating in middle-aged women. Clin Psychol Rev 31 (4):515-524. doi:10.1016/j.cpr.2010.12.002 20. Goodman EL, Baker JH, Peat CM, Yilmaz Z, Bulik CM, Watson HJ (2018) Weight suppression and weight elevation are associated with eating disorder symptomatology in women age 50 and older: Results of the gender and body image study. Int J Eat Disord 51 (8):835-841. doi:10.1002/eat.22869

21. McLean SA, Paxton SJ, Wertheim EH (2010) Factors associated with body dissatisfaction and disordered eating in women in midlife. Int J Eat Disord 43 (6):527-536. doi:10.1002/eat.20737

22. Reboussin BA, Rejeski WJ, Martin KA, Callahan K, Dunn AL, King AC, Sallis JF (2000) Correlates of satisfaction with body function and body appearance in middle- and older aged adults: The activity counseling trial (ACT). Psychol Health 15 (2):239-254. doi:10.1080/08870440008400304 23. Perrig-Chiello P, Höpflinger F (2009) Die Baby-Boomer. Eine Generation revolutioniert das Alter. NZZ Verlag, Zürich, Switzerland 24. Bochud M, Chatelan A, Blanco J-M, Beer-Borst S (2017) Anthropometric characteristics and indicators of eating and physical activity behaviors in the Swiss adult population: Results 
from menuCH 2014-2015. The Federal Office of Public Health and the Food Safety and Veterinary Office, Bern

25. Fairburn CG, Beglin SJ (2008) Eating Disorder Examination Questionnaire (6.0). In:

Fairburn CG (ed) Cognitive Behavior Therapy and Eating Disorders. Guilford Press, New York, pp 309-313

26. Carrard I, Rebetez MM, Mobbs O, Van der Linden M (2015) Factor structure of a French version of the Eating Disorder Examination-Questionnaire among women with and without binge eating disorder symptoms. Eat Weight Disord 20 (1):137-144. doi:10.1007/s40519014-0148-x

27. Cash TF (2000) MBSRQ user's manual. 3rd edn. Old Dominion University Press, Norfold, VA

28. Untas A, Koleck M, Rascle N, Borteyrou X (2009) Psychometric properties of the French adaptation of the multidimensional body self relations questionnaire-appearance scales. Psychol Rep 105 (2):461-471. doi:10.2466/PR0.105.2.461-471

29. Fredrickson BL, Roberts TA, Noll SM, Quinn DM, Twenge JM (1998) That swimsuit becomes you: sex differences in self-objectification, restrained eating, and math performance. J Pers Soc Psychol 75 (1):269-284

30. Lasher KP, Faulkender PJ (1993) Measurement of aging anxiety: development of the Anxiety about Aging Scale. Int J Aging Hum Dev 37 (4):247-259

31. Schaumberg K, Reilly EE, Anderson LM, Gorrell S, Wang SB, Sala M (2018) Improving prediction of eating-related behavioral outcomes with zero-sensitive regression models. Appetite 129:252-261. doi:10.1016/j.appet.2018.06.030

32. Jackman S (2008) pscl: Classes and Methods for R Developed in the Political Science Computational Laboratory. Stanford University. Department of Political Science, Stanford 
University, Stanford, California. R package version 0.95. URL http://CRAN.Rproject.org/package=pscl.

33. Mond JM, Hay PJ, Rodgers B, Owen C, Beumont PJ (2004) Validity of the Eating Disorder Examination Questionnaire (EDE-Q) in screening for eating disorders in community samples. Behav Res Ther 42 (5):551-567. doi:10.1016/S0005-7967(03)00161-X

34. American Psychiatric Association (2013) Diagnostic and Statistical Manual of Mental Disorders, fifth edition (DSM-5) American Psychiatric Association, Washington DC 35. Kornstein SG, Kunovac JL, Herman BK, Culpepper L (2016) Recognizing Binge-Eating Disorder in the Clinical Setting: A Review of the Literature. Prim Care Companion CNS Disord 18 (3). doi:10.4088/PCC.15r01905

36. ANSES (2010) Avis de l'ANSES relatif à la demande d'évaluation des risques liés aux pratiques alimentaires d'amaigrissement. Agence nationale de sécurité sanitaire de l'alimentation, de l'environnement et du travail, Paris

37. Allaz AF, Bernstein M, Van Nes MC, Rouget P, Morabia A (1999) "Weight loss preoccupation in aging women": a review. J Nutr Health Aging 3 (3):177-181 38. Roy M, Payette H (2012) The body image construct among Western seniors: a systematic review of the literature. Arch Gerontol Geriatr 55 (3):505-521.

doi:10.1016/j.archger.2012.04.007 